\title{
De Buenos Aires a Santa María. La (no) escritura de Juan María Brausen como artificio de construcción y escapatoria
}

Recibido: 14 de febrero de 2020

Aceptado: 30 de marzo de 2020

Resumen: En el presente artículo se analiza el proceso de ambigua invención literaria mediante el cual Juan María Brausen, protagonista de la novela La vida breve (1950), de Juan Carlos Onetti, trastoca la dimensión espacio-temporal de la ciudad en que habita, Buenos Aires, desplazándose a la ciudad que imagina y verbalmente construye, Santa María, como consecuencia de la escritura fallida de un guion cinematográfico. Se demuestra y concluye que en la subjetividad escritural a partir de la que Juan María Brausen franquea los límites entre lo que es y lo que idealiza, operan los siguientes principios filosóficos: I) la methexis platónica; ॥) la imaginación primaria y secundaria; III) la Condición y la Persona, el impulso sensitivo y el impulso formal; IV) el Espíritu, la oscilación y la imagen; v) la voluntad de creación; $\mathrm{VI}$ ) las ideas como pensamientos deíficos infinitos, independientes e incesantemente móviles; y VII) la alegría primitiva.

Palabras clave: Juan Carlos Onetti; La vida breve; proceso de invención literaria; desplazamiento escritural; platonismo y romanticismo

\section{From Buenos Aires to Santa María. The (Non) Writing of Juan María Brausen as a Construction Artifice and Getaway}

\footnotetext{
(c) (i)(2)

La Revista Estudios es editada por la Universidad de Costa Rica y se distribuye bajo una Licencia Creative Commons Atribución-NoComercial-CompartirIgual 3.0 Costa Rica. Para más información envíe un mensaje a 
Dossier: La escritura en los desplazamientos: viajes, expediciones y naufragios

Abstract: This article analyses the ambiguous process of literary invention carried out by Juan María Brausen, Juan Carlos Onetti's novel The Brief Life (1950) protagonist, to disrupt the space and time dimension of the city he lives in, Buenos Aires, relocating himself to Santa María, the city he builds in his imagination as an outcome of the failure in trying to write a film script. The article proves and substantiates the conclusion that Juan María Brausen's subjectivity as a failed writer, which allows him to break the limits between reality and introspective hallucination, consist of the following philosophical principles: I) the platonic methexis; II) the primary and secondary imagination; III) the Condition and the Persona, the sensitive drive and the formal drive; IV) the Spirit, the oscillation and the image; v) the will of creation; VI) the ideas as infinite, independent, unceasingly moving, godlike thoughts; and VII) the primeval joy.

Keywords: Juan Carlos Onetti; The Brief Life; literary invention process; writing in motion; Platonism and Romanticism

orden del vacío preparaba una palabra que no sabía su nombre Eunice Odio

El presente artículo analiza el proceso creativo, de ambigua invención literaria, mediante el cual Juan María Brausen, protagonista de la novela La vida breve (1950), de Juan Carlos Onetti, gradualmente trastoca la dimensión espaciotemporal de la ciudad en que habita, Buenos Aires, desplazándose a la ciudad que imagina y verbalmente construye, Santa María, como consecuencia no premeditada de la escritura fallida de un guion cinematográfico.

La subjetividad a partir de la que Juan María Brausen franquea los límites entre lo que es y lo que idealiza, instigado por una pulsión narrativa secreta y ágrafa, será dilucidada desde I) la methexis o participación platónica; ॥) la imaginación primaria y secundaria (Samuel Taylor Coleridge, Biographia Literaria); III) la Condición y la

\section{(c) (i) (2)}

La Revista Estudios es editada por la Universidad de Costa Rica y se distribuye bajo una Licencia Creative Commons Atribución-NoComercial-CompartirIgual 3.0 Costa Rica. Para más información envíe un mensaje a 
Dossier: La escritura en los desplazamientos: viajes, expediciones y naufragios Persona, el impulso sensitivo y el impulso formal (Friedrich Schiller, La educación estética del hombre); IV) el Espíritu, la oscilación y la imagen (Johann Gottlieb Fichte, Fundamentos de la teoría de la ciencia); v) la voluntad de creación (Arthur Schopenhauer, El mundo como voluntad y representación); VI) las ideas como pensamientos deíficos infinitos, independientes e incesantemente móviles (Friedrich von Schlegel, Fragmentos); y VII) la alegría primitiva (Friedrich Nietzsche, Voluntad de poder).

La ruta de análisis arriba descrita parte de la siguiente inquietud: ¿cómo y cuándo es que Juan María Brausen ejecuta, si cabe, una escritura que jamás se le manifiesta incontrovertiblemente al lector? Las pautas de su celoso, si bien equívoco trabajo de escritor, son plausibles desde el capítulo "I. Santa Rosa”, de la "Primera parte" del gran texto fundacional onettiano. La vecina de Juan María Brausen, la Queca, desde el departamento contiguo, despereza en él tendencias intrusivas, sin que presencie sino solamente imagine, reconstruyéndolo a partir de ruidos y silencios provocativos, un mundo deseable, cercano y vedado, que pese a no serle accesible no lo priva de participar en la ficción que a sí mismo se suministra, entretejiéndola como una idea simultánea a las eróticas suposiciones que lo intrigan. Juan María Brausen entra, por la vía de sus cavilaciones, a la privacidad de una prostituta, con lo que Juan Carlos Onetti varía, por primera vez en su novela, la noción platónica de la methexis ( $\mu \varepsilon \dot{\varepsilon} \varepsilon \xi ı \zeta)$ o participación, término que se discute en los diálogos “Hipias Mayor", "Fedón”, así como en República, y que alude a una de las formas de relación entre las ideas y el mundo sensible, o entre las ideas mismas. Donde se analiza quizá más detenidamente el irresuelto sustantivo es en "Parménides", coloquio en el que se propone que las cosas son en la medida en que participan de las ideas, planteándose la pregunta de si una cosa participa de toda la idea que le sirve de modelo o si participa solamente de una parte de ella (Platón, 2002).

Juan María Brausen, en La vida breve, participa mediante un voyerismo auditivo

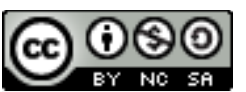

La Revista Estudios es editada por la Universidad de Costa Rica y se distribuye bajo una Licencia Creative Commons Atribución-NoComercial-CompartirIgual 3.0 Costa Rica. Para más información envíe un mensaje a revistaestudios.eeg@ucr.ac.cr. 
Dossier: La escritura en los desplazamientos: viajes, expediciones y naufragios de las ideas que lo inquietan respecto de la Queca y las cuales más tarde moldearán, en la realidad, la concreción heteronímica de sus ensoñaciones en la identidad alterna de macró que adoptará bajo el alias "Arce", cuando ultraje a su objeto de deseo, cimentando además y eventualmente, desde el mundo sensible bonaerense, Santa María, una provincia urdida con palabras dentro de su psique; palabras a las que eximirá, empero, de su representación alfabética.

Juan Carlos Onetti le otorga a su Juan María Brausen la destreza y el derecho impunes a interactuar de una manera gradualmente inseparable, a un punto física, real, con sus ideas, primordialmente descriptivas y a través de las que ase una proximidad que lo fusiona con lo desconocido, expandido éste por una especulación que anecdóticamente procesa y ornamenta los estímulos de los que emana:

...su voz, sus pasos, la bata de entrecasa y los brazos gruesos que yo le suponía pasaban de la cocina al dormitorio (...) Debía de estar [la Queca] en la cocina, agachada frente a la heladera, rebuscando, refrescándose la cara y el pecho con el aire helado donde se endurecían olores vegetales, aceitosos (1970, pp. 435-436).

La invención, en las antípodas de su apartamento escindidas por una pared, le permite a Juan María Brausen trasladarse subjetivamente a un espacio distinto al que ocupa y que ya lo hastía porque carece de novedad al compartirlo con Gertrudis, la esposa "sabida de memoria" (p. 436) a quien le ha sido cercenado un seno para contrarrestar las ramificaciones del cáncer que la aquejara.

Escuchando lo que sucede al reverso de su muro, y resignificándolo, Juan María Brausen vuelve a ser consciente de que alberga un talento promisorio: "recordé mi esperanza de un milagro impreciso que haría para mí la primavera" (p. 437). Dicho milagro impreciso, al que aludiera sarcásticamente el propio Juan Carlos Onetti en un diálogo con Emil Rodríguez Monegal recogido por Jorge Rufinelli en Onetti (1973), no es otro que el de la escritura, que devendrá justamente imprecisa, no delineada y evanescente, al plantearse Juan María Brausen, el publicista, la

La Revista Estudios es editada por la Universidad de Costa Rica y se distribuye bajo una Licencia Creative Commons Atribución-NoComercial-CompartirIgual 3.0 Costa Rica. Para más información envíe un mensaje a 
Dossier: La escritura en los desplazamientos: viajes, expediciones y naufragios

realización del guion cinematográfico que lo instruye a elaborar su jefe Stein. Tal milagro impreciso no ocurrirá debido en gran parte a la inhibición, no exenta de un ímpetu poético, que le produce a Juan María Brausen meditar sobre la herida fresca de Gertrudis: "No me sería posible escribir el argumento para cine de que me había hablado Stein mientras no lograra olvidar aquel pecho cortado, sin forma ahora, aplastándose sobre la mesa de operaciones como una medusa, ofreciéndose como una copa" (p. 437).

Juan María Brausen superpone a la instrucción de Stein y a sus posibilidades de desencadenar el milagro impreciso, a saber, la escritura, la imagen de insuperable desamparo que postró a Gertrudis durante la cirugía. La inminencia y la promesa de un manuscrito se agitan bajo la evocación de una simetría dolorosamente vulnerada: el seno faltante de Gertrudis confronta a Juan María Brausen, desde un cuerpo al que antes veneró, con lo inconcluso de sí mismo, con una parte de su vida que también le ha sido arrebatada. La hondura simbólica de la cicatriz postoperatoria es el núcleo de la novela: un vacío dispuesto para ser llenado, sustituido, si no con un acto dispensado, otra vez, por el milagro impreciso, al menos con lo que éste, nebuloso, contagiado por esa oquedad en Gertrudis, será capaz de brindarle a Juan María Brausen, no sólo para que lo suplante, sino aun para que lo amplíe dentro de sí mismo, trazando nada menos, paulatinamente, el ulterior destino de su exilio hacia la en primera instancia solamente ilusoria y posteriormente verídica Santa María, sitio en el que la dualidad Gertrudis-Juan María Brausen, escindida por el escalpelo de la desgracia, podrá intentar la restauración de su armonía en los autorretratos ficticios de los personajes Elena Sala-Díaz Grey.

La cohabitación con Gertrudis, mutilada, reaviva el encarecimiento, la urgencia y la intuición de lo milagroso al tiempo que exacerba la certeza de la escritura inevitablemente incompleta, inalcanzable del guion cinematográfico que haría para mí la primavera. De tales angustia y desesperanza, y como si se maridaran ambos campos de vaciedad en una sola tensión poética, irá brotando un reino análogo,

\section{(๑) $\odot \odot$}

La Revista Estudios es editada por la Universidad de Costa Rica y se distribuye bajo una Licencia Creative Commons Atribución-NoComercial-CompartirIgual 3.0 Costa Rica. Para más información envíe un mensaje a 
Dossier: La escritura en los desplazamientos: viajes, expediciones y naufragios imperfecto, sí, pero que puede prescindir de aquello que el libreto exige: una sintaxis de corroboración perceptible, codificada en una serie de cuartillas. Fatalmente incentivada por la "ablación de mama" (p. 438), la "obra" dúctil de Juan María Brausen germina en lo desgarrado.

La methexis o participación que la cercanía seductiva de la Queca y la estela de la enfermedad de su cónyuge han puesto en marcha en Juan María Brausen, se abastece sustancialmente de un tipo de imaginación que se parangona con las categorías primaria y secundaria que Samuel Taylor Coleridge pormenoriza en Biographia Literaria (1817), específicamente en el capítulo 13 de uno de los textos pilares para el romanticismo inglés, titulado "On the Imagination, or Esemplastic Power":

The IMAGINATION then I consider either as primary, or secondary. The primary IMAGINATION I hold to be the living Power and prime Agent of all human Perception, and as a repetition in the infinite mind of the eternal act of creation in the infinite I AM. The secondary I consider as an echo of the former, co-existing with the conscious will, yet still as identical with the primary in the kind of its agency, and differing only in degree, and in the mode of its operation. It dissolves, diffuses, dissipates, in order to recreate; or where this process is rendered impossible, yet still at all events it struggles to idealize and to unify. It is essentially vital, even as all objects (as objects) are essentially fixed and dead (2014, p. 206).

Juan María Brausen, azuzado por la promiscuidad ilícita de la Queca, y proyectándose hacia los puntos cada vez más distantes a los que sus fantasías propenden a transportarlo, reacciona al vacío alegorizado por la sutura de Gertrudis, y, reabriendo esa sutura con el filo de sus abstracciones, agudiza la facultad primaria de la imaginación que para Coleridge hace factible una repetition in the infinite mind of the eternal act of creation in the infinite I AM. Juan María Brausen está ya invocando, al insubordinarse contra lo esencialmente fijo y muerto-el amor por Gertrudis ya dilapidado por la supresión mutua del erotismo-su Yo infinito. Más adelante, y ya cuando esta tendencia creativa a multiplicarse se torne más dinámica, transferirá a sus criaturas, condicionadas por él en Santa María a repetir 
Dossier: La escritura en los desplazamientos: viajes, expediciones y naufragios eternamente los actos que les imponga, parte de su poder vital de percepción, como llama Coleridge a la facultad secundaria de la imaginación; un poder vital que, además, disuelve, difumina y disipa para recrear, cualidades éstas que corresponderían con las gradaciones de sentido y con la devolución de lo animado a un rastro de cáncer con la cual Juan María Brausen resignificará los estragos que ensombrecen a Gertrudis.

En el episodio de la novela “Il. Díaz Grey, la ciudad y el río”, ocurre por consecuencia que los escarceos con lo ficticio de Juan María Brausen, acuciados por el espionaje acústico de la Queca y por la fijación por el busto amputado de Gertrudis, obren la súbita aparición de un correlato exponencial de lo imaginado. Surge, sin más, el doctor Díaz Grey, personaje que se le presenta, con intransigencia, a Juan María Brausen mientras consuela a Gertrudis, presa ésta de un decaimiento convaleciente. Luego de la metamorfosis ejercida por un médico sobre el cuerpo de su esposa, Juan María Brausen-recreando su Yo Infinito-crea a otro médico a su imagen y semejanza, quien será además su alter ego y a partir del cual fundará su civilización (a)literaria, disolviendo, difuminando y disipando, así, aquel pecho cortado, sin forma ahora de Gertrudis. La figura del profesionista que sana-pero también del que permuta fisonomías, del que cercena-, es reclamada con la conciencia de incurrir en una personificación que irradiará dos extremos antitéticos e indisolubles: la esperanza y la pérdida.

La imaginación en su estrato secundario, aquélla que para Coleridge disuelve, difumina y disipa va complejizándose constantemente hasta coincidir con la que describiera Friedrich Schiller en su tratado La educación estética del hombre (1794): la imaginación, a saber, en tanto suma de las fuerzas interiores del ser humano que lo asisten para conducirlo al equilibrio entre la razón y la sensibilidad, forjando además sus habilidades contemplativas y así no le sean indiferentes las manifestaciones de la Belleza.

\section{(c) (1) (-)}

La Revista Estudios es editada por la Universidad de Costa Rica y se distribuye bajo una Licencia Creative Commons Atribución-NoComercial-CompartirIgual 3.0 Costa Rica. Para más información envíe un mensaje a revistaestudios.eeg@ucr.ac.cr. 
Dossier: La escritura en los desplazamientos: viajes, expediciones y naufragios

Contrastándola con las cuarta y onceava misivas de las veintisiete que componen el amplísimo y polémico estudio de Schiller, es discernible en la prosa de Juan Carlos Onetti el desencadenamiento de las capacidades con las que Juan María Brausen frisa, aunque sin encarnarlo, el ideal arquetípico del genio romántico en tanto creador a plenitud, posponiendo indefinidamente articular el guion cinematográfico que La vida breve insinúa y del que muestra sólo sus estadios intermitentes de afiebrada preconcepción. Sin embargo, y pese a su tal vez fallida maduración creativa, Juan María Brausen libera dentro de sí a otro hombre ideal, a uno que subyace a la grandeza del genio pero que se emancipa mediante la quimérica invención de un relato con el que subvertir lo real.

Para Schiller, la imaginación conduce al más alto nivel de abstracción, en el cual el hombre experimenta dos instancias en las que dicha abstracción debe detenerse, para reconocerlos como su límite: una que cambia, y que es la Condición, y una que persiste, que es la Persona (1967, p. 74). En La vida breve, Juan María Brausen cambia sustancialmente gracias o a pesar de sus visiones introspectivas, y con ello modifica su Condición: ya no sólo es un entrometido que divaga sobre el universo paralelo de la Queca, sino que ha fincado, a la manera de un ente divino, un universo propio, del que será Padre mítico, epíteto con el que lo distingue Jorge Rufinelli en "Onetti. En busca del origen perdido", artículo que data de 1974 y que se compendia en la publicación La Vida Literaria. Tal rarefacción afecta a Juan María Brausen mientras reflexiona sobre la escritura, recordando con obsesiva recurrencia que Stein le había encargado un guion cinematográfico, convenciéndolo de que deseaba hacerlo y convenciéndose después a sí mismo de semejante anhelo, al asegurarle, inconvincente, a Gertrudis: "Cuando estés mejor, me pondré a escribir" (p. 441), aprestándose no más que a inconsistentes e insomnes devaneos que harán imposible que se le expidan, tarde o temprano y como arbitrariamente calcula, "trece mil pesos, por lo menos, por el primer argumento" (p. 442).

\section{(c) (i) (-)}

La Revista Estudios es editada por la Universidad de Costa Rica y se distribuye bajo una Licencia Creative Commons Atribución-NoComercial-CompartirIgual 3.0 Costa Rica. Para más información envíe un mensaje a 
Dossier: La escritura en los desplazamientos: viajes, expediciones y naufragios

Juan María Brausen, por lo demás, condiciona su proyecto escritural con esta sentencia, que lo inauguraría: "Todo tiene que partir de ahí" (p. 442), refiriéndose con este todo a la visión genésica del doctor Díaz Grey tras éste habérsele manifestado. Pero dicho todo se reduce más bien a nada, a un límite de folios en blanco dentro y fuera del que se bifurcan las abstracciones imaginativas merced a las cuales su identidad interna, además, titubea. El surgimiento espontáneo, en su mente, del doctor Díaz Grey y de la provincia en que se ubica su consultorio, no quedan inscritos en documento alguno, lo que parece no frustrar en su totalidad la progresión de un argumento que tarde o temprano será-“Una semana o dos, no más" (p. 442) —puesto en tinta, y el cual al mismo tiempo está, diríamos, preconscientemente desplegándose en el ahora enrarecido del lector de La vida breve.

En la doceava carta de La educación estética del hombre, Schiller clasifica dos fuerzas opuestas-la Stofftrieb (o tendencia sensible), y la Formtrieb (o tendencia formal) - , que operan a su vez decisivamente en la subjetividad escapista de Juan María Brausen, y que contribuyen, bregando cada una por reafirmarse, al objetivo anómalo de fraccionarlo, antes que de depararle un balance. El teórico germano las desglosa como sigue:

...we are impelled by two opposing forces which, since they drive us to the realization of their object, may aptly be termed drives. The first of these, which I will call the sensuous drive [Stofftrieb], proceeds from the physical existence of man, or his sensuous nature. Its business is to set him within the limits of time, and to turn him into matter [...] The sensuous drive does indeed demand change; but it does not demand the extension to this to the Person and its domain, does not demand a change of principles. The formal drive [Formtrieb] insists on unity and persistencebut it does not require the Condition to be stabilized as well as the Person, does not require identity of sensation (pp. 70-86).

La tendencia sensible, natural de Juan María Brausen, la que lo instaura en las demarcaciones del tiempo y la que lo convierte en materia, está demandándole un cambio, pero sin que éste se extienda a su Persona y a sus dominios, y sin que 
Dossier: La escritura en los desplazamientos: viajes, expediciones y naufragios vulnere sus principios como Juan María Brausen. Por el contrario, la tendencia formal lo llama a conservar la unidad y la persistencia, descartando así el cambio del primer impulso. Para efectos de dichas unidad y persistencia, por cierto, no se requiere de acuerdo a Schiller una identidad de sensación, ni tampoco una estabilidad entre la Condición y la Persona. Es decir: la tendencia sensible o natural, como se verá más adelante en la historia, se cumple con el enmascaramiento que Juan María Brausen maquina para sí mismo, haciéndose pasar, por un ansia de cambio, por "Arce", con lo que no modificará sino que ocultará su Persona, y tampoco perturbará los principios que lo siguen definiendo como Juan María Brausen, pues éste continúa, si bien disfrazado de "Arce", construyendo minuciosamente la Santa María que lo empodera en su condición de creador, mientras se repone de las conmociones ocasionadas por la flaqueza de Gertrudis.

Juan María Brausen lidia, pues, con dos encarnizadas propensiones, derivadas del decurso en el que lo instaura la imaginación schilleriana: la del cambio y la de la forma unificada, persistente. Al batirse contra la realidad, introspectiva y extrovertidamente, las canaliza no sin desesperación en un esfuerzo creativo-y paradojalmente, también, autodestructivo-al amalgamarlas y trascender su entorno miserable. "Erigiendo" Santa María, ahueca su mano sobre una mancha azul que antes fue el seno de Gertrudis, en un movimiento de arquitectura emocional no exento de consonancias espirituales, con el que aspira a restituir una Belleza que sea duradera.

Juan María Brausen no renuncia un solo instante a su trágica circunstancia de lúcido intermediario entre las alteridades que, a causa de lo anterior, incita y lo disocian. Cavila respecto del mundo de Buenos Aires en el que Gertrudis resiste, languidece, y respecto del otro, el de Santa María, que despunta, incontenible y etéreo, no escrito, dentro de su imaginario, conformando poco a poco estos dos universos uno solo, indivisible.

\section{(๑) $\odot \odot$}

La Revista Estudios es editada por la Universidad de Costa Rica y se distribuye bajo una Licencia Creative Commons Atribución-NoComercial-CompartirIgual 3.0 Costa Rica. Para más información envíe un mensaje a revistaestudios.eeg@ucr.ac.cr. 
Dossier: La escritura en los desplazamientos: viajes, expediciones y naufragios

Juan María Brausen se referirá a la cimentación de Santa María como a una cosa que comienza, inevitable (p. 442), y a consecuencia de la cual su identidad se irá entreverando, desde el parecido físico hasta el pensamiento y la gestualidad, con la del galeno Díaz Grey, si bien con una desconcertante salvedad: los dos se dejan distinguir, inconfundibles y distintos, a los ojos del lector de La vida breve, en una recíproca y escurridiza aleación. Juan María Brausen en Buenos Aires, Díaz Grey en Santa María, intercambian sus voces narrativas y sus actos y ensoñaciones llegan incluso a interpolarse en virtud de los desplazamientos que genera, con sutileza, la pluma onettiana.

El guion cinematográfico irá resultando, luego, innecesario, y su escritura a fin de cuentas prescindible, pues aun sin existir entrega a Juan María Brausen una posesión, si bien ficticia en una primera etapa, materialmente verdadera luego, ufanándolo con aprensiva vehemencia: "Ahora la ciudad [Santa María] es mía, junto con el río y la balsa que atraca en la siesta. Ahí está el médico con la frente apoyada en la ventana (...) en un momento cualquiera yo pondré contra la borda de la balsa a una mujer" (p. 447).

Los hechos a ocurrir en Santa María dependen del absoluto y omnipotente capricho enunciativo de Juan María Brausen, al que Juan Carlos Onetti exime de toda obligación estrictamente sintáctica, tornando existente de por sí la dimensión que sus enunciados pregramaticales formulan. Con el uso indiscriminado, cuasi divino, de palabras intangibles, Juan María Brausen decidirá en un momento cualquiera--aunque nunca en una página-el encuentro de Díaz Grey y de la mujer que, sin saberlo éste, arribará muy pronto a un constructo ya idílico, ya distópico llamado Santa María para obsesionarlos a ambos.

De las tendencias opuestas, sensible y formal, de que se nutre la imaginación y a las que se vuelve por cierto a referir Schiller, ampliándolas, en la carta decimonovena de su tratado, se abordará ahora la pulsión creativa de Juan María Brausen en correspondencia con aquello que el filósofo alemán Johann Gottlieb

\section{(c) (i) (-)}

La Revista Estudios es editada por la Universidad de Costa Rica y se distribuye bajo una Licencia Creative Commons Atribución-NoComercial-CompartirIgual 3.0 Costa Rica. Para más información envíe un mensaje a revistaestudios.eeg@ucr.ac.cr. 
Dossier: La escritura en los desplazamientos: viajes, expediciones y naufragios Fichte concibiera para sí como imaginación, atendiendo suplementariamente a sus conceptos oscilación (Schweben), e imagen (Bild).

En Fundamentos de la teoría de la ciencia (1794-1795), Fichte entiende por Espíritu (Geist), imaginación productiva, y a ésta la describe a su vez como la maravillosa capacidad sin la que los mecanismos del alma humana no pueden ser comprendidos, y la cual oscila entre opuestos que, simultáneamente, se unifican en un ir y venir que hace posible la fabricación de una imagen (Bild) que momentáneamente los reconcilia. Esta imagen es en un principio amorfa, indeterminada, y luego se va clarificando gracias, otra vez, a la oscilación entre contrarios antedicha, que la moldea y determina. De manera, entonces, que aquel que imagina no ve sólo un objeto inespecífico, sino que le va asignando ciertas propiedades y excluye otras para completarlo mediante la mencionada oscilación entre opuestos que es, por cierto, una empresa autoreflexiva, centrípeta y centrífuga, que aspira a preservar, en el ámbito de oposiciones en que acontece, la unidad verdadera del ser (citado en Kinlaw, 2001, pp. 122-124)

Cuando Juan María Brausen ausculta, en ausencia de Gertrudis, el muro que lo separa de la Queca, es cuando más comprometidamente retoca a Díaz Grey, quien en un momento cualquiera, en el muelle de Santa María, verá atracar una balsa de la que descenderá una tripulante atractiva. Juan Carlos Onetti bosqueja así una cinta de Moebius en la que entroncan y fluyen dos expectativas y dos tránsitos lo mismo paralelos que diefridos: en Buenos Aires, Juan María Brausen aguarda, pronto, el arribo de Gertrudis desde Temperley, a donde ha ido a reunirse con su madre, en tanto el galeno santamariano aguarda, pronto, el arribo de Elena Sala desde las abstracciones de Juan María Brausen: espera espejística la de ambos que reconcilia, en la imagen suspensiva del muelle, el juego de oposiciones y aun participaciones entre lo real y lo ideal que enfebrecen la imaginación productiva, el Espíritu (Geist) del protagonista onettiano: "La mujer [Elena Sala] llegaría por la madrugada, con cualquiera o sola; Gertrudis volvería de Temperley por la mañana”

\section{(c) (i) (-)}

La Revista Estudios es editada por la Universidad de Costa Rica y se distribuye bajo una Licencia Creative Commons Atribución-NoComercial-CompartirIgual 3.0 Costa Rica. Para más información envíe un mensaje a revistaestudios.eeg@ucr.ac.cr. 
Dossier: La escritura en los desplazamientos: viajes, expediciones y naufragios (p. 456). Esta oscilación entre un acontecimiento real y otro ficticio, contrapuestos y sincrónicos en la poética sibilina de Juan María Brausen, alcanza después un grado de compenetración categórico, en la imagen del consultorio de Díaz Grey que, como la del muelle, se concibe subjetiva, momentáneamente, y que será entreabierta desde la realidad bonaerense por Juan María Brausen para intercalarla con la realidad santamariana: "Gertrudis tendría que saltar del marco plateado del retrato para aguardar su turno en la antesala de Díaz Grey (...) Ella, la remota Gertrudis de Montevideo, terminaría por entrar en el consultorio de Díaz Grey" (p. 457).

El salto y la entrada, sin embargo, no se efectúan, sino que se suspenden y postergan en la página de La vida breve que los incardina. Gertrudis no se desplaza desde el marco plateado del retrato exhibido en un apartamento de Buenos Aires hacia el consultorio de Díaz Grey en Santa María debido a una contención escritural de Juan María Brausen que se antoja preventiva, en tanto el salto y la entrada apurarían el advenimiento irreversible, que sucede a fin de cuentas, de la cosa inevitable ya comentada párrafos arriba, a saber: la expansiva y tal vez, en el fondo, no deseada arquitectura de Santa María, en la que se atomizarán—o, retomando a Coleridge, se disolverán, difuminarán y disiparán-Juan María Brausen y Gertrudis, remodelados. Si Juan María Brausen fijara en papel su guion cinematográfico, las esclusas entre los mundos análogos se ocluirían, inhabilitando las impredecibles interconexiones y oscilaciones entre Buenos Aires y Santa María con las que, mitómano, aliena un discurso incontenible, aunque mecanográficamente enmudecido. Juan María Brausen dilata su borrador en una pausa que también perturba las inmediaciones de Santa María, donde Díaz Grey acecha el cauce del río. La compenetración entre ambos hemisferios de esta suerte de palíndromo narrativo onettiano es asaz hipnótica: Elena Sala—o "el reconquistado cuerpo de muchacha" (p. 457) de Gertrudis-, Ilegaría a Santa María, sin que llegue aún; lo mismo que la Gertrudis avejentada, rota, retornaría, sin que retorne aún, a Buenos Aires. Juan María Brausen prefiere, templando el arco de la prosa, la interrelación-

\section{(๑) $\odot \odot$}

La Revista Estudios es editada por la Universidad de Costa Rica y se distribuye bajo una Licencia Creative Commons Atribución-NoComercial-CompartirIgual 3.0 Costa Rica. Para más información envíe un mensaje a revistaestudios.eeg@ucr.ac.cr. 
Dossier: La escritura en los desplazamientos: viajes, expediciones y naufragios la oscilación-del microcosmos de su apartamento con el de Santa María, sin que las "dos páginas, o una, siquiera" (p. 456), de su script, estanquen las imágenes aleatorias que su movilidad expectante, imaginaria y mórbida, va enhebrando.

Juan María Brausen, él sí ubicuo, de algún modo salta, sale y entra de Buenos Aires y Santa María sin que pueda un solo momento aquietar su imaginación, la cual también de acuerdo a Fichte, y visiblemente en La vida breve, reconcilia lo irreconciliable, y, aún más, une lo que no puede unirse: en el caso de la novela, une el cuerpo de Gertrudis, rejuvenecido y completo, al reencarnar ficcionalmente en el de Elena Sala, voluptuoso.

La imaginación, lo mismo desde la óptica de Fichte, representa lo que de otra manera no puede ser representado, pero demanda de cualquier manera serlo. En La vida breve, por supuesto, aquello no representado que demanda su representación equivale a la propia Santa María, que por indisposición o calculada dejadez Juan María Brausen nunca representa en texto pero que, pese a ello, aquélla le demanda o él se demanda a sí mismo edificar, por lo que el publicista procede a su ambiguamente sólido andamiaje echando mano de varias imágenes unificadas.

Para dar término a la consulta de los razonamientos de Fichte: éste añade que la imaginación oscila entre la incapacidad y el requerimiento de representaciones. Juan Carlos Onetti ensambla estas dos instancias claramente antitéticas-incapacidad $y$ requerimiento-en las representaciones marginales que, sin concretarlas Juan María Brausen como escenas en guion cinematográfico alguno, avivan el entorno intermitente y frágil de Santa María, que va evolucionando si bien su demiurgo se halla anclado en una onírica suspensión que coarta su voluntad escritural, misma que se discutirá a continuación al trasluz de la filosofía schopenhaueriana.

Como es bien sabido, en El mundo como voluntad y representación (1819), Arthur Schopenhauer otorga primacía al cuerpo sin reposo en tanto autoridad que 
Dossier: La escritura en los desplazamientos: viajes, expediciones y naufragios somete cualquier atisbo de albedrío y que subyuga, con sus apetitos insaciables, al hombre y a los simulacros que rigen la naturaleza sensitiva de sus actos: "Every action of my body, then, is the appearance of an act of will: and this act is just my will itself, in general and in its entirety (and therefore also my character) expressing itself again in the presence of certain motives" (2010, p. 132).

Juan María Brausen habría querido inhibir la voluntad impositiva, asumida por Schopenhauer como la directriz que manipula las apetencias, cuando profiere: "no al alcohol, no al tabaco, un no equivalente para las mujeres" (p. 477). Abstencionismos éstos que se correlacionarían con otro, a su vez perentorio: el de la escritura del guion cinematográfico, actividad ésta que de perpetrarla Juan María Brausen, le recompensaría con la ganancia del pago hipotético de los trece mil pesos con los cuales financiar un resarcimiento de su matrimonio con Gertrudis y por ende saciar sus repentinas necesidades sociofisiológicas: "Dejo la agencia, nos vamos a vivir afuera, donde quieras, tal vez se pueda tener un hijo" (p. 442).

Pero la escritura de Juan María Brausen, como se ha subrayado, no despunta en lo sintáctico, y, si se la escudriña desde la tesis schopenhaueriana, no pasa de ser la difusa apariencia de "palabras y actos nocturnos" (p. 459) que se murmuran y que en cierta medida se cumplen, pero sin que el lector corrobore aquellas oraciones que, no pergeñadas "directamente" por Juan Carlos Onetti, animan el universo de Santa María.

La voluntad, como se ha citado, se expresa a sí misma in the presence of certain motives. ¿Y cuáles son estos ciertos motivos detonantes en la novela onettiana? Juan María Brausen los experimenta, otra vez, cuando ilusoriamente garabatea su guion cinematográfico, absorto en sus roces hipersensibles con lo real, de vuelta del mundo imaginario y oscilante desde el cual se ha contemplado y redescubierto: "Calmándome y excitándome cada vez que mis pies tocaban el suelo, creyendo avanzar en el clima de una vida breve en la que el tiempo no podría bastar para comprometerme, arrepentirme o envejecer" (p. 479).

\section{(c) (i) (2) (2)}

La Revista Estudios es editada por la Universidad de Costa Rica y se distribuye bajo una Licencia Creative Commons Atribución-NoComercial-CompartirIgual 3.0 Costa Rica. Para más información envíe un mensaje a revistaestudios.eeg@ucr.ac.cr. 
Dossier: La escritura en los desplazamientos: viajes, expediciones y naufragios Calmándose y excitándose_alarmas corporales opuestas, caóticas, a través de las que se manifiesta, implacable, la voluntad-, y mientras deambula por su apartamento, pendiente de las degradaciones moral de la Queca y anatómica de Gertrudis, Juan María Brausen, divagando sobre Santa María, escapa entre las rendijas de su muda verbalización hacia su provincia etérea, desde la que invierte el ángulo de autorreflexión no sólo para redescubrirse, sino para saberse también detenido en las antecámaras de un sedentarismo por lo demás efímero donde el tiempo no podría bastar para comprometerme, arrepentirme o envejecer. La ralentización onettiana es de una espesura vertiginosa. A la voluntad escritural fallida de Juan María Brausen la cerca un tiempo ya casi extinto, insuficiente como aquélla: un tiempo que a su vez no dista de una mera representación y que Schopenhauer conceptualizó adhiriéndose a la premisa kantiana del tiempo y del espacio como elaboradas abstracciones, al admitir que éstas pueden ser intuidas de inmediato, aun sin haberlas experimentado antes, y, lo más importante a propósito de lo que se argumenta en este artículo, considerándolas como un grupo especial y autónomo de representaciones en tanto intuiciones puras y sin contenido (p. 27). Juan Carlos Onetti capta el tiempo en su novela como una cuenta regresiva exigua, breve, tanto, que no bastará siquiera para que su Juan María Brausen envejezca; es decir, como una cuenta regresiva que se intuye pura, no vulnerada por el envejecimiento de un hombre y a un ápice, como éste, de carecer por completo de contenido. Calmándose y excitándose, escribiendo y no, el agente publicitario suspende, dentro de los parámetros estrechos de una temporalidad densa, mínima e ilusoria, el "dibujo", la "larga frase inicial" (p. 460) del guion cinematográfico. Y en esta misma suspensión de voluntad, dentro de la que la escritura será siempre incierta o quedará desfasada, es en donde va imposiblemente aplazándose a la vez que configurándose la espectral y esplendorosa Santa María.

\section{(c) (i) (-)}

La Revista Estudios es editada por la Universidad de Costa Rica y se distribuye bajo una Licencia Creative Commons Atribución-NoComercial-CompartirIgual 3.0 Costa Rica. Para más información envíe un mensaje a 
Dossier: La escritura en los desplazamientos: viajes, expediciones y naufragios

Este paradójico acabado autónomo, cíclico, merced al que las ideas vagas y luego meticulosas sobre Santa María fagocitan, remite a la definición que en el medular Fragmentos (1797-1800) propusiera Friedrich von Schlegel, precursor del romanticismo alemán influenciado por cierto por Fichte: "10. Ideas are infinite, independent, unceasingly moving, godlike thoughts" (1971, p. 242). Y es que el doctor Díaz Grey en tanto idea concebida por el Padre mítico Juan María Brausen, es una idea infinita, independiente e incesantemente móvil, como en esencia lo son todas para Schlegel, y reproducirá una y otra vez, entre otras pantomimas anecdóticas, un coqueteo irresoluble con Elena Sala. Sin consignarlas Juan María Brausen, tampoco, en prosa, la radiante Elena Sala, la balsa y la corriente del río de Santa María fluyen como un todo, acompasada y cíclicamente, y son pese a la pausa y toque de queda del (no) escritor a quien aguardan para que las reavive, llevando a cabo entretanto una espiral coreográfica de viñetas-otra vez: la repetition in the infinite mind of the eternal act of creation de Coleridge-instalándolas en las periferias ignotas de su boceto. Díaz Grey y Elena Sala, infinitos e incesantemente móviles, reiteran los patrones histriónicos a los que los condiciona Juan María Brausen en tanto casi no les depara nuevos desenvolvimientos.

En el capítulo “XXI. La cuenta equivocada”, Juan María Brausen ha perfeccionado ya la mentira de ser "Arce" ante los ojos y sentimientos volátiles de la Queca, con quien se ha atrevido finalmente a filtrar, mientras, en Santa María, su galeno comienza a columbrarlo. Juan María Brausen, desde los parapetos de su mundo ficticio, desde su preciada propiedad, será entrevisto por su criatura adánica. Al no haber escrito, al no bloquear la línea roja divisoria entre realidad y ficción con una más definitiva muralla sintáctica, tales realidad y ficción han permanecido como hendeduras dúctiles por las cuales el acecho de Díaz Grey, ahora recíproco y correlativamente posesivo, es además religioso: "No pensaba en la mujer, invocaba mi nombre en vano" (p. 559). En esta compleja oscilación subvertida-uno de los entes imaginarios de Juan María Brausen imaginándolo, ahora, a él-Juan María

\section{(C) $(\Theta \odot \odot$}

La Revista Estudios es editada por la Universidad de Costa Rica y se distribuye bajo una Licencia Creative Commons Atribución-NoComercial-CompartirIgual 3.0 Costa Rica. Para más información envíe un mensaje a revistaestudios.eeg@ucr.ac.cr. 
Dossier: La escritura en los desplazamientos: viajes, expediciones y naufragios Brausen le confiere a Díaz Grey, su mesías o su profeta corrupto, la pronunciación de una suerte de plegaria a la que no responderá, ya que como divinidad embrionaria y como identidad perpetuamente dislocada, preferirá una existencia indeterminada, tal como lo fue la escritura de la que proviniera el doctor en tanto preámbulo no sintáctico a una manifestación de carácter teológico y, de suyo, incierta.

La invocación en vano antedicha ha tenido lugar en una ciudad de la que al avance de capítulos de La vida breve se nos participa que su antigüedad es tal que incluso ostenta ya una estatua ecuestre para honrar la valentía de un ancestro inmemorial de Díaz Grey. Una ciudad que, como se propuso al principio, planificara Juan María Brausen al desasosegarlo su contacto con el organismo frágil de Gertrudis apenas ésta sorteó, malherida, un envite atroz, quirúrgico, en su duelo con la muerte. Una ciudad, en suma, hacia la que se fugará su evanescente arquitecto, y la cual es un palimpsesto no sólo de la descomposición de su esposa sino también de la del Buenos Aires del que ha de huir; una descomposición que le ha deparado el brote, antes verbal e imaginario, y ahora útil al contemplarlo en un mapa, de un atajo transitable: "Tracé una cruz sobre el círculo que señalaba a Santa María (...) estuve cavilando acerca de la forma más conveniente de llegar a la ciudad" (p. 680).

Juan María Brausen corrobora, con lo anterior, la fundación de su propio Estado, el cual a su vez es otro de los modelos idealizados, a gran escala según el pensamiento romántico, del Espíritu (Geist), lo que por tanto confiere a la imaginación productiva del anti-héroe onettiano facultades de creación que rebasan las meramente (a)literarias y que, milagrosamente imprecisas, han devenido un orbe factual, geográficamente discernible, en el que había ejercido, antes de precipitarse a su encuentro, un mandato distante y a una vez íntimo, paladeando iterativo la sensación de ser los entes que ya lo habitan y experimentando, incluso, lo que los predispone a padecer. La urdimbre del guion cinematográfico, suspendida

\section{(๑) $\odot \odot$}

La Revista Estudios es editada por la Universidad de Costa Rica y se distribuye bajo una Licencia Creative Commons Atribución-NoComercial-CompartirIgual 3.0 Costa Rica. Para más información envíe un mensaje a 
Dossier: La escritura en los desplazamientos: viajes, expediciones y naufragios en contra de y por medio de una voluntad que desplegara representaciones no premeditadas para colmarse, se materializa entonces en un Estado en el que a dicha voluntad, aproximativamente schopenhaueriana, se le sumaría la de poder, elucubrada por Friedrich Nietzsche en Voluntad de poder (1901). Y es que cuando Juan María Brausen decreta, refiriéndose a los lugareños de Santa María: "Todos eran míos, nacidos de mí, y les tuve lástima y amor" (p. 685), su exultante declaración remite a las observaciones nietzscheanas que se transcriben:

Likewise our love to the beautiful: it also is our shaping will. The two senses stand side-by-side; the sense for the real is the means of acquiring the power to shape things according to our wish. The joy in shaping and reshaping - a primeval joy! We can comprehend only a world that we ourselves have made (1968, p. 272).

El sentido de lo real sólo le ha sido redescubierto a Juan María Brausen al devenir aquél un elemento primario gracias al que ha ido liberando su poder, antes impreciso y ahora fehacientemente milagroso y el cual se ratifica en la consulta, alquímicamente verosímil, del mapa: un poder con el que da sustancia y halo vitalicios a sus representaciones presintácticas. Su alegría al formar y reformar aquello que acontece en Santa María es, por lo demás, un goce primitivo insuflado por sus criaturas, a las que les tuve lástima y amor, y exacerbado por el entorno aun inabarcable al que dio origen y del que se jacta: "amé también cada paisaje desconocido de la tierra" (p. 685).

La declaración autosuficiente de Juan María Brausen, regocijándose al admirar con amor y lástima a quienes cohabitan en aquel caserío vuelto por su arbitrio no sólo metrópoli sino incluso vasta tierra, es un éxtasis primigenio que celebra lo mismo que lamenta la consumación, por muy atrabiliaria en La vida breve, de una obra que lo redime como creador, complaciéndolo. Nietzsche acota: "Ultimately, it is not only the feeling of power, but the pleasure in creating and in the thing created; for all activity enters our consciousness as consciousness of a 'work'” (p. 349).

\section{(c) (i) (-)}

La Revista Estudios es editada por la Universidad de Costa Rica y se distribuye bajo una Licencia Creative Commons Atribución-NoComercial-CompartirIgual 3.0 Costa Rica. Para más información envíe un mensaje a revistaestudios.eeg@ucr.ac.cr. 
Dossier: La escritura en los desplazamientos: viajes, expediciones y naufragios

Al no haber ultimado el guion cinematográfico, Juan María Brausen fraccionó, sublimándola, su identidad, alcanzando sin embargo una primitiva, aunque no menos contundente, condición de artista cuya obra no anidó más allá del plano de la conciencia y que, sin ser escrita, le ha dispensado la victoria insólita de migrar, encubriendo al asesino de la Queca, Ernesto, al sitio que pendiera de su noctámbulo susurro para no desmoronarse y que, al franquearlo, auspiciosamente lo ilumina: "Encendían las luces de la plaza cuando llegamos a Santa María" (Onetti, 1970, p. $682)$. 
Dossier: La escritura en los desplazamientos: viajes, expediciones y naufragios

\title{
REFERENCIAS BIBLIOGRÁFICAS
}

Breazeale, D. (Ed). (2001). New Essays in Fichte's Foundation of the Entire Doctrine of

Scientific Knowledge. New York, United States: Humanity Books.

Coleridge, S. T. (2014). Bibliographia Literaria. Edinburgh, United Kingdom: Edinburgh

University Press.

Nietzsche, F. (1968). Will to Power. New York, United States: Random House.

Onetti, J.C. (1970). Obras completas. Ciudad de México, México: Aguilar.

Platón. (2002). Diálogos. Madrid, España: Gredos.

Rufinelli, J. (1973). Onetti. Montevideo, Uruguay: Biblioteca de Marcha.

Schiller, F. (1967). On the Aesthetic Education of Man. Oxford, United Kingdom: Oxford

\author{
University Press.
}

Schopenhauer, A. (2010). The World as Will and Representation. New York, United States: Cambridge University Press, 2010.

Schlegel, F. (1971). Lucinde and the Fragments. Minneapolis, United States: University

of Minnesota Press.

\section{(c) (1) 8 ()}

La Revista Estudios es editada por la Universidad de Costa Rica y se distribuye bajo una Licencia Creative Commons Atribución-NoComercial-CompartirIgual 3.0 Costa Rica. Para más información envíe un mensaje a revistaestudios.eeg@ucr.ac.cr. 